\title{
A influência do inglês no processo de ensino/aprendizagem de alemão por aprendizes brasileiros de terceiras línguas: Abordagens e métodos de investigação
}

[The influence of English on the teaching/learning process of German as a third language for Brazilian learners: Approaches and investigation methods]

http://dx.doi.org/10.1590/1982-8837175197

Bianca Ferrari ${ }^{1}$

\begin{abstract}
The main purpose of this paper is to present an overview of the results of an empirical research involving adult learners of German as a foreign language with previous knowledge of English. It focuses on some of the processes related to the learning/teaching of third languages, taking into consideration that the German language is usually learned as a second foreign language, especially after English. The main questions of the research are based on positive transfer processes as well as linguistic interference observed in a group of 50 learners of German, levels A1 to B1 of the Common European Framework of Reference for Languages. As for what concerns the relationship between English and German, the assumption that English exerts an important role in the learning process of German could be confirmed, being the etymological relationship between languages one of the most important elements in order to determine the occurrence of cross-linguistic influence. On the other hand, the linguistic interference that results from the coexistence of both languages in the learner's brain demands the development of a plurilingualism didactic that embraces alternative methods for the teaching/learning of German as a second foreign language in Brazil.
\end{abstract}

Key-words: Plurilingualism; teaching/learning of German as L3; cross-linguistic influence; German after English.

Resumo: O objetivo principal deste artigo é apresentar uma visão geral dos resultados obtidos em uma pesquisa empírica envolvendo aprendizes adultos de alemão como língua estrangeira com conhecimentos prévios de inglês. O foco deste artigo recai sobre os processos envolvidos no ensino/aprendizagem de terceiras línguas, levando-se em consideração que a língua alemã é comumente aprendida como uma segunda língua estrangeira após o inglês. Os principais questionamentos da pesquisa estão baseados em processos de transferência positiva, bem como na interferência linguística observada em um grupo de 50 aprendizes de alemão dos níveis A1 a

\footnotetext{
${ }^{1}$ Universidade de São Paulo, Faculdade de Filosofia, Letras e Ciências Humanas, Departamento de Letras Modernas, Programa de Pós-Graduação em Língua e Literatura Alemã. Email: bianca.ferrari@usp.br
} 
Ferrari, B. - A influência do inglês no processo de ensino/ aprendizagem de alemão

B1 do Quadro Europeu Comum de Referência para as Línguas. Ao que concerne a relação entre as línguas alemã e inglesa, a afirmação de que o inglês exerce um papel importante na aprendizagem de alemão pôde ser confirmada, sendo o parentesco etimológico entre as duas línguas um dos mais importantes fatores para se determinar a ocorrência de influência interlinguística. Por outro lado, a interferência linguística resultante da coexistência de ambas as línguas demanda o desenvolvimento de uma didática do plurilinguismo que compreenda métodos alternativos para o ensino/aprendizagem de alemão como segunda língua estrangeira no Brasil.

Palavras-chave: Plurilinguismo; ensino/aprendizagem de alemão como L3; influência interlinguística; Alemão após Inglês.

\section{Introdução}

Em consequência das recorrentes mudanças sociais e econômicas observadas nas últimas décadas, que trouxeram maior mobilidade às populações e uma intensificação dos contatos interculturais, a importância da aprendizagem de línguas estrangeiras ampliou seu destaque, tornando-se comuns cenários nos quais aprender mais de uma língua estrangeira é uma realidade consolidada. Nesse contexto, o avanço de línguas consideradas "regionais", como é o caso do alemão, ganhou novos contornos, no geral impulsionados por políticas de manutenção e promoção linguística, como a política elaborada pelo Conselho da Europa, que prevê que cada cidadão europeu deva dominar duas línguas estrangeiras além de sua língua materna (CONSELHO DA EUROPA 2001).

A partir desse cenário de difusão e incentivo ao ensino/aprendizagem de mais de uma língua estrangeira, foi proposta a criação de um termo que englobasse os falantes de diversas línguas além da materna, os sujeitos plurilíngues. O plurilinguismo, em seu sentido mais amplo, não diz respeito à simples coexistência de diferentes idiomas em um país ou região, estando mais relacionado às experiências linguísticas de um indivíduo. Inseridas nesse contexto, todas as línguas aprendidas pelo sujeito servem à construção de sua competência comunicativa, para a qual todos os conhecimentos e capacidades linguísticas colaboram e na qual as línguas se relacionam e interagem (CONSELHO DA EUROPA 2001: 7).

Entre as cerca de 6.909 línguas faladas no mundo, o alemão ocupa o décimo lugar no ranking de língua materna mais falada (SAVEDRA 2011: 296), contabilizando, no total, aproximadamente 125 milhões de falantes de alemão como primeira ou 
Ferrari, B. - A influência do inglês no processo de ensino/ aprendizagem de alemão

segunda língua ${ }^{2}$. Apesar de seu expressivo número de falantes, o alemão ainda sofre, mundialmente, com as consequências da concentração dos sistemas educacionais em praticamente uma só língua estrangeira, no caso o inglês, que, por razões econômicas e geopolíticas, é considerada língua franca. Uma estatística que comprova tal afirmação é a que compara o percentual de aprendizes de inglês e alemão em continente europeu, visto que, enquanto $32 \%$ dos europeus se dedicam ao aprendizado de inglês como língua estrangeira, somente $9 \%$ fazem o mesmo em relação à língua alemã (cf. KRUMM 2003: 38). A partir dessas considerações, pode-se deduzir que a aprendizagem da língua alemã é caracterizada, em muitas regiões, pela sua posterioridade ao aprendizado da língua inglesa.

No Brasil são detectáveis dois cenários que compreendem a relação entre as línguas alemã e inglesa. No primeiro cenário, a aprendizagem da língua alemã ocorre posteriormente à da língua inglesa enquanto no segundo cenário a aprendizagem de ambas as línguas é concomitante. Para os dois cenários é válido afirmar que a influência do inglês na aprendizagem do alemão apresenta-se como uma variável possível, em especial se levarmos em consideração que ambas as línguas pertencem ao ramo germânico das línguas indo-europeias, com semelhanças em diversas áreas, como o vocabulário, que conta com mais de 600 palavras “comuns" (NEUNER 2009), entre anglicismos, internacionalismos e empréstimos lexicais realizados diretamente do inglês. Consequentemente, a criação e o estabelecimento do campo de estudo Alemão como Língua Estrangeira após Inglês (DaFnE) mostrou-se necessária na tentativa de compreensão dos fenômenos envolvendo o ensino/aprendizagem sequencial e/ou concomitante das línguas alemã e inglesa.

A partir das breves considerações acima tecidas, é objetivo deste artigo apresentar, teórica e empiricamente, como se manifesta a influência da língua inglesa sobre o ensino/aprendizagem de alemão como terceira língua por aprendizes brasileiros. $\mathrm{O}$ artigo inicia-se com a delineação do panorama dos estudos sobre a terceiras línguas e sua relação com a influência interlinguística, bem como por uma apresentação das áreas de contato entre as línguas alemã e inglesa. A seguir, serão feitas considerações acerca da condução da pesquisa que deu origem ao corpus. Na seção de análise dos resultados, são apresentados alguns exemplos extraídos do corpus de pesquisa, os quais, por sua

\footnotetext{
${ }^{2}$ Fonte: Instituto Goethe. Disponível em http://www.goethe.de/ins/br/lp/lrn/wdl/ggd/pt5479068.htm Acesso em: 25 Mai. 2013.
} 
Ferrari, B. - A influência do inglês no processo de ensino/ aprendizagem de alemão

vez, devem ser descritos e analisados. Por fim, haverá uma discussão dos resultados obtidos na pesquisa, seguida pelas considerações finais.

\section{$2 \bigcirc$ ensino/aprendizagem de terceiras línguas e a influência interlinguística}

Até meados da década de 1990, estudos que abordassem o ensino/aprendizagem de terceiras línguas, como é o caso da língua alemã, comumente uma L3 ou Lx (x $\geq 3$ ) (HUFEISEN 2003: 648), eram pouco comuns, visto que, até aquele momento, os pesquisadores não consideravam fazer uma distinção clara entre o aprendizado da primeira e da segunda língua estrangeira (GASS \& SELINKER 2008: 5). Consequentemente, alguns dos questionamentos concernentes especificamente ao ensino/aprendizagem de terceiras línguas ficaram, por um longo período de tempo, subordinados às respostas das pesquisas na área do ensino/aprendizagem de segundas línguas, pois se partia do pressuposto de que a aprendizagem de uma L2 e de uma L3, bem como de suas línguas subsequentes, transcorria de forma semelhante, senão idêntica.

Entretanto, a observância, por parte de professores em sala de aula, do aparecimento de interferências entre as diversas línguas estrangeiras dos aprendizes chamaram a atenção para o fato de que todas as línguas estrangeiras que um sujeito possui em seu repertório linguístico interagem entre si e são passíveis de estabelecer relações independentes da língua materna (cf. BAUSCH \& HEID 1990; HUFEISEN 1991).

HUFEISEN (1991) constatou, durante a correção de textos de aprendizes de alemão como língua estrangeira, o aparecimento de construções que, apesar de conhecidas, não correspondiam ou não se adequavam às regras do alemão padrão, como nos exemplos *den anderen Tag e *Ich bin in Ihr Angebot sehr interessiert. Através da busca por similaridades entre as construções dos aprendizes e os sistemas de sua(s) língua(s) previamente aprendidas/adquiridas, a pesquisadora pôde verificar que tais fenômenos não se deixavam explicar pela influência da língua materna desses aprendizes, no caso o francês, mas de sua primeira língua estrangeira, o inglês. Tal percepção chamou a atenção dos pesquisadores de que os fenômenos relacionados ao trilinguismo são mais diversos e, consequentemente, mais complexos do que aqueles 
Ferrari, B. - A influência do inglês no processo de ensino/ aprendizagem de alemão

relacionados ao bilinguismo (cf. VOORWINDE 1981 apud AUER \& WEI 2007: 106). Partindo dessa perspectiva os estudos envolvendo a aprendizagem de uma L2 foram gradualmente se afastando daqueles que envolviam a aprendizagem de uma L3 ou (L3 + n) (cf. NEUNER 2009).

Para que seja possível analisar a interação das várias línguas estrangeiras do sujeito, é necessário atentar para diferentes mecanismos de influência entre as línguas, tais como a subprodução ou superprodução de estruturas específicas, substituições e/ou alterações de itens da língua-alvo e interpretações errôneas na compreensão de itens (cf. MURPHY 2005: 3). É a partir da análise de tais mecanismos que nos é possível avaliar processos como o da interferência linguística e da transferência linguística positiva.

SELINKER (1984 apud SELINKER 1992: 208), principal representante da interlíngua, aqui entendida como um sistema intermediário entre a língua materna e a língua-alvo do aprendiz, adota o termo transferência linguística para denominar o conjunto de comportamentos, processos e restrições envolvidos na produção linguística de falantes de diversas línguas. GASS \& SELINKER (2008) retomam a questão da transferência na interlíngua ao defini-la como a influência de uma L2 sobre qualquer outra língua que o sujeito possua em seu repertório. Dessa forma, os autores enfatizam que, para que seja possível compreender melhor a transferência na interlíngua, é necessária uma análise que vá além da língua nativa e da língua-alvo, englobando também outras línguas aprendidas pelo sujeito. Entretanto, o emprego do termo transferência linguística em situações de produção/recepção linguística envolvendo duas ou mais línguas é considerado questionável por retomar princípios behavioristas. A partir disso foi proposto outro termo, mais neutro em relação às teorias, denominado influência interlinguística, que abarca fenômenos como a transferência, a interferência, evitação, empréstimo e aspectos relacionados a perda linguística (cf. SHARWOOD-SMITH \& KELLERMANN 1986: 125).

Para De Angelis \& Selinker (2001: 43), todos os sistemas linguísticos presentes no cérebro do aprendiz interagem concomitantemente na produção de sua interlíngua, sendo a possibilidade de transferência proporcional ao número de línguas de um determinado sujeito. Essa situação, por sua vez, torna as relações entre as diferentes línguas de um sujeito plurilíngue cada vez mais complexas se levado em consideração que o falante tem a tarefa de manter os diferentes sistemas linguísticos separados durante as tarefas de produção linguística evitando, consequentemente, eventuais 
Ferrari, B. - A influência do inglês no processo de ensino/ aprendizagem de alemão

transferências advindas da língua materna, a interferência entre línguas intermediárias e a transferência reversa da interlíngua do aprendiz, entre outros fenômenos compreendidos pela influência interlinguística.

$\mathrm{Na}$ medida em que os estudos sobre as interações entre diferentes línguas estrangeiras foram avançando, a percepção que os pesquisadores haviam construído sobre a noção do erro também foi modificada, passando de uma abordagem pautada quase que exclusivamente na noção de interferência linguística para outra, mais centrada nos processos de transferência positiva (VOGEL 1992). Essa nova abordagem focaliza, em grande parte, os conhecimentos e capacidades linguísticas anteriormente adquiridas pelos aprendizes e tem relações com as características dos aprendizes de L3.

\section{Alemão após Inglês para aprendizes brasileiros}

Ao analisarmos o ensino/aprendizagem de alemão como língua estrangeira no Brasil, fica claro que a distância tipológica entre o alemão e o português, língua românica, é maior do que a distância entre as línguas alemã e inglesa, línguas germânicas. Consequentemente, para os falantes de português como língua materna, o inglês pode funcionar como um fator de auxílio em uma primeira aproximação com o alemão, na medida em que conscientiza esses falantes que alguns fenômenos do alemão são iguais ou parecidos aqueles do inglês, fato passível de facilitar sua aprendizagem. Partindo dessa breve constatação segue-se a descrição de algumas áreas de contato entre o alemão e o inglês.

O vocabulário da língua alemã é composto por uma série de internacionalismos comuns entre o português, o inglês e o alemão, tais como Telefon e palavras com raízes gregas e latinas, como Taxi, Musik e Polizei. Não obstante essas semelhanças, ainda é maior o número de palavras comuns entre o alemão e o inglês, que compreende não somente as palavras supracitadas como também os anglicismos, tais como Jeans, Internet, Party, Interview e palavras compostas, como em Schulbuch. HUFEISEN (1993) foi a principal autora a compilar uma sequência de áreas de experiência nas quais se encaixam as mais de 600 palavras comuns (NEUNER 2006: 4) entre o alemão e o inglês, entre elas nomes dos meses, estações do ano, caracterização de pessoas e coisas, alimentação, vestuário, partes do corpo, doenças, disciplinas escolares, esporte, comunicação em massa e política. Entretanto, na área do vocabulário também existem 
Ferrari, B. - A influência do inglês no processo de ensino/ aprendizagem de alemão

os falsos cognatos, como bekommen - become, que correspondem a, aproximadamente, $3 \%$ do vocabulário comum alemão/inglês.

$\mathrm{Na}$ gramática, o parentesco etimológico entre as línguas também oferece vantagens aos aprendizes de alemão. Quanto às principais áreas de contato podem ser citadas: modelos de construção de frases simples, como em Ich bin Patrick - I am Patrick; concordância na área das palavras funcionais, como em artigos, preposições e conjunções; formação dos tempos verbais, verbos regulares e irregulares e partículas modais (NEUNER 1996: 216).

Por outro lado, as áreas da pronúncia e da ortografia exigem maior atenção durante a aprendizagem de alemão como terceira língua, pois nessa área o inglês oferece menos correspondências, sendo necessário um tratamento consciente das áreas divergentes em sala de aula. Palavras com significados adjacentes e/ou idênticos e pronúncias e entonação distintas, como é o caso de hard - hart; water - Wasser; sea See, communication - Kommunikation; technology - Tecnologie necessitam maior treino em sala de aula, bem como a entonação das frases, também diferente. Na ortografia os aprendizes tendem a transpor, para o alemão, a grafia de palavras semelhantes no inglês, como em apple - Apfel.

\section{A pesquisa empírica}

\subsection{Contextualização e participantes da pesquisa}

Os resultados a serem apresentados neste artigo foram coletados ao longo do segundo semestre de 2010 nos cursos de extensão Alemão no Campus, oferecidos à comunidade da Universidade de São Paulo, formada por alunos, professores, funcionários e interessados na língua alemã em geral. Os cursos oferecidos por monitores da Graduação e da Pós-Graduação em Letras são compostos por cinco níveis iniciais (A1.1 a B1.1) do Quadro Europeu Comum de Referência para as Línguas.

Os 50 aprendizes pesquisados tinham idades entre 19 e 64 anos, ensino superior em curso ou já finalizado e procuraram os cursos de alemão motivados por uma necessidade de se aperfeiçoar profissionalmente e nos estudos. Quanto ao seu repertório linguístico, este se demonstrou extremamente vasto e diversificado, sendo que as sequências linguísticas Inglês e Alemão (30\% dos participantes) e Inglês, Espanhol e 
Ferrari, B. - A influência do inglês no processo de ensino/ aprendizagem de alemão

Alemão (22\% dos participantes) foram as que concentraram um maior número de informantes, perfazendo grande parte da amostra selecionada para análise.

Para que possíveis interferências advindas da influência de demais línguas estrangeiras fossem evitadas foram selecionados aqueles aprendizes que possuíam exclusivamente as línguas inglesa e alemã em seu repertório, sendo que, em todos os casos analisados, o alemão foi aprendido posteriormente ao inglês.

\subsection{Metodologia}

A coleta de informações linguísticas dos aprendizes foi realizada por meio de um questionário de pesquisa distribuído aos alunos dos cursos de Alemão no Campus, dos níveis Básico I a Básico V. O questionário de pesquisa distribuído aos participantes era idêntico, não separando os aprendizes pela sua competência em língua alemã, e continha uma proposta de produção textual, na qual os aprendizes deviam produzir um texto do gênero cartão postal com base em elementos previamente fornecidos pela pesquisadora. Tais elementos, por sua vez, foram selecionados a partir da análise das áreas de contato entre as línguas alemã e inglesa no intuito de elicitar o emprego de vocabulários e construções frasais passíveis de gerar influência interlinguística.

Os itens previamente selecionados para elicitação compreendiam vocabulário comum entre as línguas alemã e inglesa (Bus - bus), atividades de lazer (ins Theater gehen - go to the theatre) e alimentação (Bier - Beer), bem como a adjetivação em geral, presente nas opiniões que os aprendizes deveriam fornecer ao longo do texto. A produção textual proposta também englobava construções nos tempos presente e passado e itens gramaticais passíveis de gerar transferências positivas, tais como o emprego do comparativo (Hier ist besser als dort - Here is better than there) e as construções com verbo modal (Ich will - I will). Ademais, construções passíveis de ocasionar interferências também foram adicionadas, como no emprego de verbos separáveis (ausruhen), que se assemelham em parte aos phrasal verbs do inglês. Dentre os itens não explicitados na proposta, porém necessários para o encadeamento do texto, podem ser elencados: construções no infinitivo (ins Kino zu gehen - to go to the movies), expressões fixas (Spass haben - have fun) e o emprego de preposições (bei by). 
Ferrari, B. - A influência do inglês no processo de ensino/ aprendizagem de alemão

A escolha, por parte da pesquisadora, por este método de coleta deu-se pelo seu caráter introspectivo (cf. ALBERT \& MARX 2010: 51), visto que a coleta de material linguístico por meio de corpora textual não explicita a relação entre o pesquisador e o pesquisado, livrando o material coletado de possíveis influências hierárquicas e/ou inibitórias passíveis de atrapalhar o conteúdo produzido. Aos alunos foi vetado qualquer método de consulta (dicionários, internet) e os textos não poderiam ser terminados fora do ambiente da sala de aula. Essas orientações foram fornecidas aos aprendizes investigados com o objetivo de manter a autoria das produções, diminuindo distorções no nível de proficiência linguística e conservando o caráter de produção textual em situação natural de sala de aula.

\section{Resultados da investigação: Apresentação e análise do corpus de pesquisa}

A análise qualitativa apresentada a seguir, que focaliza a influência da língua inglesa (L2) sobre a produção textual dos aprendizes em língua alemã (L3), adotou um viés funcionalista, que entende a língua como um instrumento de interação social, cuja função primeira é a comunicação (cf. DiK 1978: 4 apud CASTILHO 2011: 5). Dessa forma, as ocorrências linguísticas transcritas a seguir não foram entendidas como simples desvios da norma culta, mas preferencialmente como tentativas, por parte dos aprendizes, de comunicar algo e, consequentemente, interagir com o interlocutor do texto.

Quanto à classificação dos índices de influência do inglês (L2) sobre o alemão (L3), esta compreende os campos tradicionais de descrição linguística (cf. KRUMM et al. 2010: 174) a saber, Ortografia, Léxico-Semântica, Morfologia e Sintaxe. Entretanto, a categorização dos itens não teve a pretensão de ser absoluta, servindo mais como uma alternativa para a adequação dos itens linguísticos identificados nas produções textuais dos aprendizes. 


\subsection{Ortografia}

Como já mencionado na parte teórica deste artigo, a área da Ortografia é uma das mais suscetíveis às interferências linguísticas do inglês (L2) sobre o alemão (L3), devido a diferenças na grafia de palavras cuja forma e/ou significado são correspondentes. Dentre os exemplos coletados no corpus de pesquisa está a escrita de substantivos em letra minúscula, em especial quando a palavra em alemão possui equivalência grafêmica à do inglês, como no exemplo a seguir:

a) * Im diese moment ich nein zurückgehen wollen Brasil...

Im diese moment ${ }_{n . \text { [ing.] }}$ ich nein zurückgehen wollen Brasil...

In diesem Moment $_{n}$. will ich nicht nach Brasilien zurückgehen...

Neste momento eu não quero regressar ao Brasil...

A marcação da classe dos substantivos por meio da maiúscula faz parte de uma das regras do alemão padrão e envolve a escrita de substantivos simples, derivados e compostos (cf. DUDEN 2005: 85). Entretanto, a escrita de substantivos em letra minúscula por parte de aprendizes brasileiros de alemão como L3 após inglês é frequente tanto pela influência da língua materna quanto pela influência da primeira língua estrangeira, no caso o inglês. Outros exemplos do corpus envolvem os substantivos *sandwich; *film e *Ich, sendo este último um empréstimo claro da língua inglesa, na qual o pronome pessoal $I$ do inglês é exclusivamente escrito em maiúscula. Segundo NeUner (2009: 155), tal influência também pode ser constatada em substantivos do alemão com cognatos em inglês, como em house/*haus.

Outra área suscetível à influência do inglês no alemão é a da escrita de substantivos compostos, como salientado por VolinA (1992) em seus estudos sobre a interferência linguística. No corpus de pesquisa foram encontradas as seguintes ocorrências:

b) * Ich liebe die Bundes Liga und Bremen Fussball Club.

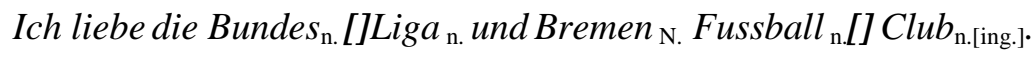

Ich liebe die Bundesliga $a_{n}$ und den Bremer Fussballclub . $_{\text {. }}$ 
Eu amo o Campeonato Alemão e o time de futebol de Bremen.

Composições são mais comuns em alemão, como no exemplo Sandstrand (sandy beach) (cf. KRUMM et al. 2010: 553). Entretanto, a influência do caráter analítico das línguas inglês e português, em oposição ao caráter sintético do alemão, podem levar os aprendizes a erros.

De acordo com NEUNER (2009: 31), problemas ortográficos costumam surgir quando os aprendizes aplicam o fenômeno da supergeneralização em suas produções, isto é, quando aplicam a mesma regra linguística de maneira padronizada. A partir disso, NEUNER (2006: 45) destacou a importância de se conscientizar os aprendizes sobre as diferenças ortográficas alemão/inglês, dentre as quais as palavras cujo " $d$ " em inglês corresponde ao " $t$ " em alemão, como em drink/trinken, e aquelas palavras cujo "sh" em inglês corresponde geralmente ao "sch" em alemão, como em shoe/Schuh. As referidas trocas foram encontradas nos seguintes exemplos do corpus:

c) *Im Bremen habe ich einen sandwich und eine super Salad gegessen!

Im Bremen habe ich einen sandwich und eine super Salad ${ }_{n . \text { [ing.] }}$ gegessen! $^{-}$

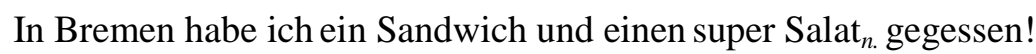

Em Bremen eu comi um sanduíche e uma super salada!

d) *Watching die game, mit warne nachts ist sehr shön.

Watching die game, mit warne nachts ist sehr shön $n_{\text {adj. }}$.

Das Spiel in warmen Nächten zu sehen, ist sehr schön ${ }_{\text {adj. }}$

Assistir ao jogo em noites quentes é muito bom.

\subsection{Léxico-Semântica}

A classificação das ocorrências de interface Léxico-Semântica compreende itens como as trocas linguísticas, o uso de falsos cognatos, processos de extensão semântica e o emprego de expressões idiomáticas e de colocações. É relevante ressaltar que, para a área da Léxico-Semântica, é de suma importância que o fator psicotipologia seja levado em consideração, pois, segundo RINGBOM (2001: 60), as semelhanças linguísticas 
Ferrari, B. - A influência do inglês no processo de ensino/ aprendizagem de alemão

percebidas pelos aprendizes entre as línguas envolvidas são comumente passíveis de gerar transferências que dizem respeito tanto à forma quanto ao significado das palavras. Ademais, a psicotipologia é um dos fatores mais decisivos nas transferências lexicais entre a L2 e a L3.

Transferências na forma das palavras, em especial as trocas linguísticas, são comuns quando falta ao aprendiz conhecimento acerca da forma a ser empregada na língua-alvo. A partir disso, os aprendizes, na sua tentativa de comunicar algo, passam a adotar itens lexicais de outras línguas de seu repertório que não a língua-alvo (cf. RINGBOM 2001: 64), como nos itens abaixo:

e) *Ale Kulturprogram ist sehr interesting.

Ale Kulturprogram ist sehr interesting adj[ing.].

Alle Kulturprogramme sind sehr interessant ${ }_{\text {adj }}$.

Todos os programas culturais são muito interessantes.

f) *Also ich habe das Restaurant Beer getrünken.

Also ich habe das Restaurant Beer ${ }_{\mathrm{n} . \text { [ing.] }}$ getrünken.

Also habe ich im Restaurant Bier ${ }_{n}$ getrunken.

Então eu tomei cerveja no restaurante.

SELINKER \& BAUMGARTNER-COHEN (1995: 116) citam a semelhança fonética e a plausibilidade de significado como fatores passíveis de gerar a fusão de interlínguas que tem como consequência, por sua vez, o aparecimento desse tipo de interferência, como demonstrado pelos exemplos acima transcritos.

Ao longo da análise do corpus também foram identificados itens lexicais emprestados diretamente da língua intermediária dos aprendizes (DENTLER 1998 apud MARX 2000), no caso, o inglês. Tais itens, por sua vez, envolvem a palavra como um todo e não somente a troca de grafemas em palavras semelhantes. Para a pesquisa, esses itens foram compreendidos como estratégias de comunicação na língua-alvo, adotadas pelos aprendizes quando estes percebem que lhes falta competência linguística em relação a certo aspecto daquilo que pretende comunicar (SELINKER 1972). Três exemplos do corpus de pesquisa ilustraram o caso: 
Ferrari, B. - A influência do inglês no processo de ensino/ aprendizagem de alemão

g) *Ich bought dich eine Wine.

Ichbought $_{\text {flex. [ing...] }}$ dich eine Wine

Ich habe $_{\text {flex.aux. }}$ dir einen Wein gekauft ${ }_{\text {flex. part. }}$.

Eu comprei um vinho para você.

h) * Ich glaube hier ist besser als Brazil.

Ich glaube hier ist besser als Brazil $_{\text {N.[ing.]. }}$

Ich glaube, dass hier besser als in Brasilien N. $_{\text {ist. }}$

Eu acho aqui melhor do que o Brasil.

i) * Ich miss dich essen, die essen hier ist nicht gut as dich, but ich been liebe die nudle mit die fleish.

Ich miss $_{\text {flex. [ing.] }}$ dich essen, die essen hier ist nicht gut $\boldsymbol{a s}_{\text {comp [ing.] }}$ dich, but conj condic[ing.] $_{\text {ich }}$ been liebe die nudle mit die fleish.

Ich vermisse $_{\text {flex. }}$ dein Essen, denn das Essen hier ist nicht so gut wie deins. Aber conj condic ich liebe Nudeln mit Fleisch.

Eu sinto falta da sua comida, pois a comida aqui não é tão boa quanto a sua, mas eu amo macarrão com carne.

Transferências linguísticas também são comuns quando relacionadas a itens lexicais tais como expressões idiomáticas e colocações. Nesses casos, o aprendiz possui conhecimento acerca da forma a ser empregada na língua-alvo, mas não de suas restrições semânticas e/ou de colocações, como representado pelo exemplo abaixo:

\footnotetext{
j) * Ich mache freund im Berlin ...

Ich mache $_{\text {flex }}$ freund $_{\text {n. }}$ im Berlin ...

In Berlin schließe $e_{\text {flex }}$ ich Freundschaften ${ }_{n} \ldots$

Eu faço amizades em Berlim...
}

Não obstante os possíveis paralelos traçados entre a expressão empregada pelo aprendiz e seu correspondente em português (fazer amigos), tal fato foi considerado de pouca relevância para a análise, visto que, de acordo com HUFEISEN (1993: 253), importa mais 
Ferrari, B. - A influência do inglês no processo de ensino/ aprendizagem de alemão

a consciência de que houve, por parte do aprendiz, uma forma de reconhecimento estrutural entre o inglês e o alemão.

\subsection{Morfologia}

Inserida no corpus de pesquisa, a área da Morfologia foi a que apresentou o menor número de interferências do inglês (L2) sobre o alemão (L3). De qualquer forma, as ocorrências constatadas são de fácil visualização e não geram dúvidas sobre a origem das interferências, se oriundas da língua materna ou da primeira língua estrangeira do aprendiz. O primeiro exemplo envolve a marcação do caso possessivo acrescido de apóstrofe, como no exemplo:

k) * Am Samstag ich flugzeuge from São Paulo to hier und komme aus Kino to see die neu Di Caprio's film, mit Debora.

Am Samstag ich flugzeuge from São Paulo to hier und komme aus Kino to see die neu Di Caprio's poss.[ing.] $_{\text {film, mit Debora. }}$

Am Samstag fliege ich von São Paulo hierher und gehe ins Kino, um den neuen Film

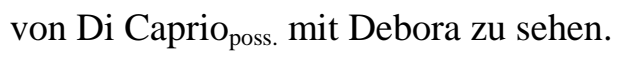

No sábado venho de avião de São Paulo para cá e fui ao cinema com a Debora para ver o novo filme do Di Caprio.

No exemplo acima, o acréscimo do $-s$ acompanhado pela apóstrofe nos apresenta um empréstimo direto do inglês, dado que tal construção não apresenta correspondentes em português.

O emprego dos tempos verbais também se mostrou uma fonte de influência da língua inglesa sobre a alemã, como no exemplo:

1) * Ich been here drei Wochen und kann nicht klagen.

Ich been $_{\text {flex.part. [ing.] }}$ here drei Wochen und kann nicht klagen.

Ich bin $_{\text {flex }}$ hier schon drei Wochen und ich kann mich nicht beklagen.

Eu estou aqui há três semanas e não posso reclamar. 
Ferrari, B. - A influência do inglês no processo de ensino/ aprendizagem de alemão

As formas verbais em inglês e em alemão apresentam uma série de semelhanças, em especial se analisadas a formação dos tempos verbais e a diferenciação entre os verbos fortes e fracos. No corpus de pesquisa foi verificada uma ocorrência envolvendo semelhanças fonéticas e interferências no emprego dos tempos verbais, como é o caso dos verbos been, do inglês e bin do alemão, empregado inadequadamente pelo fato de não haver, em alemão, uma forma contínua para cada tempo verbal como há no inglês (cf. KRUMM et al. $2010: 553$ ):

\subsection{Sintaxe}

A sintaxe é uma área visivelmente suscetível à influência interlinguística, especialmente nas áreas de ordem das palavras, orações subordinadas, artigos e sintagmas verbais (cf. ODLIN 1989: 152). Ao que concerne os resultados do corpus de pesquisa, muitos foram os aprendizes que apresentaram dificuldades no emprego do verbo na frase principal, em especial quando ela era iniciada por um advérbio (cf. VolinA 1992), como no emprego dos seguintes advérbios locativos:

m) *In Bremen das Essen ist sehr gut.

In Bremen das art.def. $_{\text {Essen }}$.. ist $_{\text {flex. }}$ sehr gut.

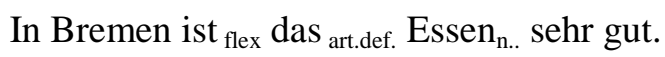

Em Bremen a comida é muito boa.

n) *Dort ich gehe ins Kino und ins Museum.

Dort $_{\text {ich }}$ pron.1sg. $_{\text {gehe }}$ flex ins Kino und ins Museum.

Dort gehe $_{\text {flex }}$ ich $_{\text {pron.lsg. }}$ ins Kino und ins Museum.

Lá eu vou ao cinema e ao museu.

o) *In Bremen ich trinke Limonade und Tee...

In Bremen ich pron.1sg. $_{\text {trink }} \boldsymbol{e}_{f l e x}$ Limonade und Tee...

In Bremen trinke flex $_{\text {ich }}$ pron.1sg. Limonade und Tee...

Em Bremen eu bebo limonada e chá. 
Ferrari, B. - A influência do inglês no processo de ensino/ aprendizagem de alemão

HUFEISEN (1991) também constatou que a ordem das palavras representa grande parte das interferências sintáticas em aprendizes de alemão (L3) após inglês (L2), sendo que a colocação do verbo na posição incorreta nas frases acima retoma a construção das respectivas frases em inglês. De um modo geral, frases que se iniciam por advérbio são passíveis de gerar interferências por conta da estrutura diferente das línguas inglês e alemão, pois, enquanto no inglês a ordem S-V-O é mantida, mesmo quando a frase inicia-se por advérbio, em alemão o verbo deve sempre ser mantido na segunda posição (V2). Entretanto, não é possível afirmar se essa interferência advém da língua materna dos aprendizes ou da primeira língua estrangeira, visto ser essa construção plausível em ambas as línguas. A questão da ordem dos elementos na frase e o uso de verbos modais (cf. HUFEISEN 1991: 88) também se mostrou problemática, como no exemplo que segue:

p) *Ich will gehen aus Chile.

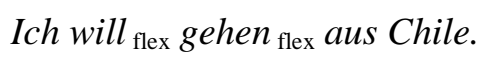

Ich will $_{\text {flex }}$ nach Chile fliegen flex $_{\text {. }}$

Eu quero ir ao Chile.

No exemplo acima, os verbos modal e infinitivo aparecem seguidos na frase (S - V1 V2 - O), não respeitando o lugar sintático dos elementos (S - V1 - O - V2), de acordo com o qual o verbo modal deveria levar o verbo no infinitivo para o final da frase. Segundo NeUnER (2009: 68), a existência de verbos modais em ambas as línguas é capaz de auxiliar a aprendizagem de alemão como L3 em seus estágios iniciais por permitir a compreensão, por parte dos aprendizes, do significado dos verbos modais e de sua função na frase. Entretanto, NEUNER e HuFEISEN (1991: 122) enfatizam a importância da conscientização dos aprendizes acerca das restrições sintáticas que acompanham o emprego dos verbos modais. Dessa forma, é relevante que os professores deixem claro aos seus alunos, seja diretamente ou por meio de uma análise contrastiva, que a frase alemã possui sua própria regra e que esta não pode ser transposta diretamente do inglês.

Também foram encontrados no corpus de pesquisa uma série de exemplos envolvendo as palavras funcionais, classe representada principalmente pelos artigos, preposições, conjunções, pronomes e interjeições. A influência do inglês na área das 
Ferrari, B. - A influência do inglês no processo de ensino/ aprendizagem de alemão

preposições (cf. HUFEISEN 1991: 81) foi marcante nas produções dos alunos dos níveis iniciais, que transpuseram preposições diretamente do inglês para o alemão, como em:

q) * Ich komme by Auto und this langen drei Uhr.

Ich komme by $y_{\text {prep. [ing.] }}$ Auto und this langen drei Uhr.

Ich komme mit ${ }_{\text {prep. }}$ dem Auto und das dauert drei Stunden.

Eu venho de carro e isso dura três horas.

r) * Dann gehe ich to Kino und to eine Fotoaustellung.

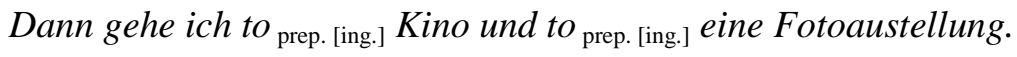

Dann gehe ich ins prep. Kino und in $_{\text {prep. }}$ eine Fotoaustellung.

Depois eu vou ao cinema e a uma exposição de fotos.

s) * Am Samstag ich flugzeuge from São Paulo to hier...

Am Samstag ich flugzeuge from prep. [ing.] $_{\text {São Paulo to }}$ prep. [ing.] hier...

Am Samstag fliege ich von ${ }_{\text {prep. }}$ São Paulo hierher ${ }_{\text {adv. }} \ldots$

No sábado eu viajo de avião de São Paulo para cá...

As preposições são entendidas como elementos suscetíveis a transferências em línguas de parentesco comprovado, como é o caso do alemão e do inglês (VoGEL, 1992; WiLliaMS \& HAMMABERG 1998). No primeiro exemplo, há o emprego da preposição by do inglês, que foi usada em analogia a preposição bei do alemão (cf. NEUNER 2009: 150). O aprendiz em questão, seja por esquecimento ou desconhecimento da forma correta Ich komme mit dem Auto, e por conhecer a preposição bei do alemão, acreditou ser plausível essa aplicação. O segundo exemplo, por sua vez, apresenta o uso direto de uma preposição em inglês to com o objetivo de indicar direção, enquanto o terceiro aprendiz, além do to, empregou a preposição inglesa from, em possível analogia ao von do alemão (cf. NEUNER 2009: 150), que, apesar de também indicar origem, não é aplicável ao caso em questão. 


\subsection{A quantificação dos índices de influência interlinguística inglês/alemão}

Ao serem contabilizados todos os índices de influência interlinguística presentes nas produções textuais dos aprendizes, chegou-se a um número de 311, dentre os quais 48 foram derivados exclusivamente da língua inglesa e 14 podem ser atribuídos tanto à língua inglesa quanto à língua materna dos aprendizes, no caso, o português brasileiro. Ademais, foram contabilizados 249 fenômenos intralinguísticos, ou seja, aqueles referentes a dificuldades dentro do próprio sistema da língua alemã. A partir dessa quantificação, a premissa de que a língua inglesa exerce influência considerável na aprendizagem de alemão como terceira língua pôde ser confirmada, visto ser responsável por, aproximadamente, $15,43 \%$ do total de erros dos aprendizes, como representado pelo Gráfico 01. Tal percentual representa mais do que o constatado por HuFEISEN (1991: 90) em sua pesquisa, na qual 9\% dos erros dos aprendizes advinham exclusivamente do inglês.

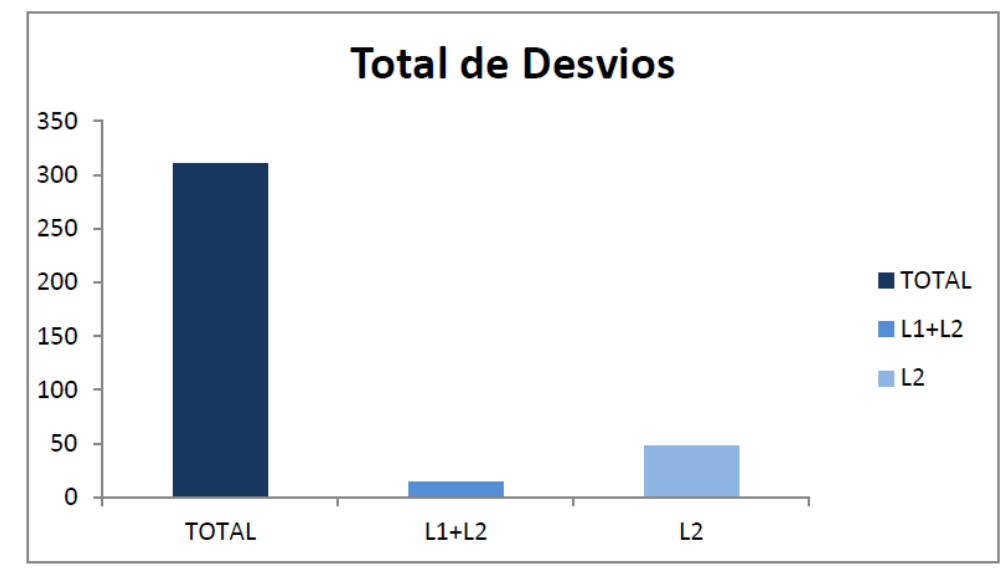

Gráfico 01: A quantificação dos erros dos aprendizes e suas fontes de influência.

Quanto à distribuição dos erros dos aprendizes por nível de aprendizagem, chegou-se à conclusão de que a influência interlinguística se mostra mais recorrente nos níveis iniciais de aprendizagem, como já assinalado por ODLIN (1989). De forma geral, há um aumento no domínio, por parte dos aprendizes, de sua competência em língua alemã, que os leva a substituir traços de sua interlíngua pelos da língua-alvo (cf. SELINKER 1972). 
Ferrari, B. - A influência do inglês no processo de ensino/ aprendizagem de alemão

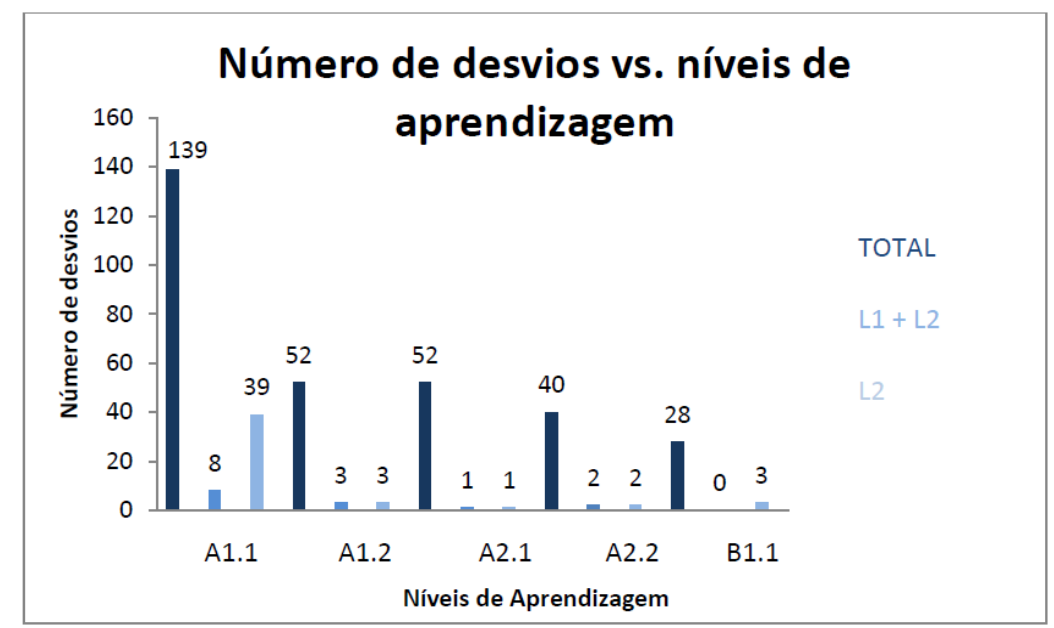

Gráfico 02: Número de desvios dos aprendizes por nível de aprendizagem

Numericamente, a influência do inglês sobre a língua alemã se dividiu de forma relativamente igualitária entre as áreas da Léxico-Semântica (36\%) e da Sintaxe (34\%), conforme Gráfico 02. Entretanto, não há uma diferença numérica significativa na comparação entre os dados dessas áreas e da área da Ortografia (24\%), pois, enquanto no campo da Ortografia foram constatados erros exclusivamente decorrentes da língua inglesa, na área da Sintaxe foram constatados uma série de fenômenos interlinguísticos decorrentes tanto do português quanto do inglês, algo que diminui as diferenças numéricas entre as áreas. Em relação ao pequeno número de erros na Morfologia (6\% do total), estes vão ao encontro das afirmações de ODLIN (1989: 152), para quem a área da morfologia é menos suscetível às interferências linguísticas.

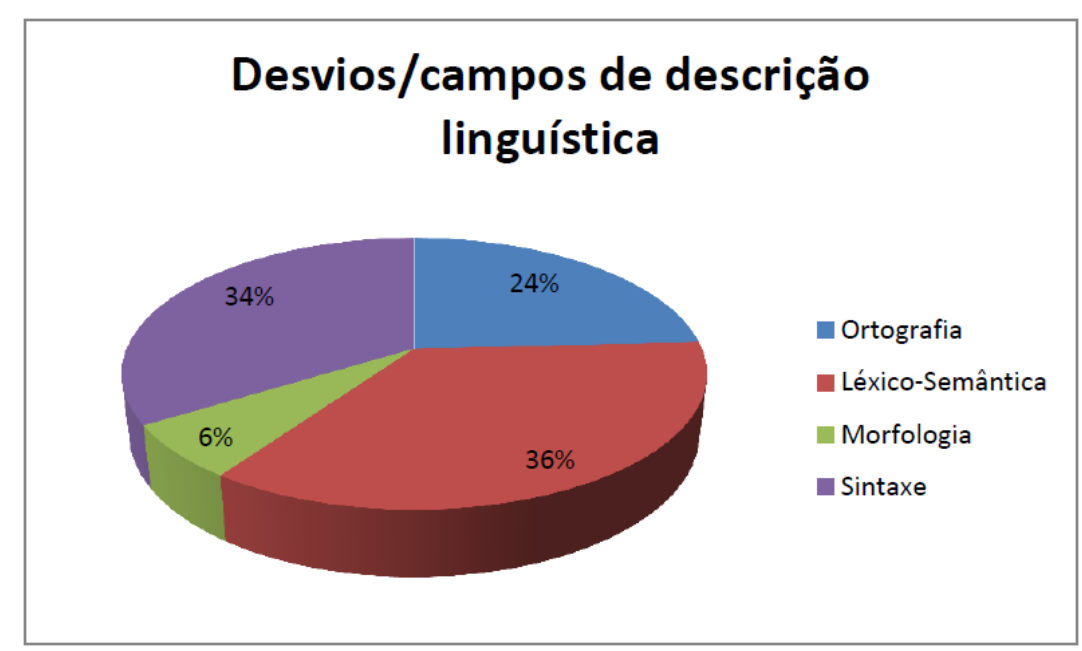

Gráfico 03: A distribuição dos erros dos aprendizes pelos campos de descrição linguística tradicionais. 


\section{Considerações finais}

Os resultados de pesquisa divulgados neste artigo confirmam, de forma geral, a premissa de que o inglês exerce um papel importante na aprendizagem do alemão por falantes nativos de português brasileiro. Tal fato, por sua vez, é especialmente válido para alunos dos níveis iniciais de aprendizagem, para os quais o inglês funciona como uma primeira inserção em língua alemã (cf.NEUNER 2009).

Quanto à influência interlinguística na aprendizagem de terceiras línguas, esta se fez presente em situações nas quais pareceu faltar aos aprendizes material linguístico na língua-alvo para atender às suas necessidades comunicativas. Nessas situações, os aprendizes investigados fizeram uso de sua competência plurilíngue ao substituir, nas produções textuais, itens lexicais do inglês a partir dos critérios de similaridade formal e de plausibilidade de significado das unidades envolvidas. Essas similaridades, por sua vez, funcionam como marcadores linguísticos, aos quais os aprendizes recorrem como forma de construir seu novo repertório linguístico a partir de outro, pré-existente (RINGBOM 1986: 134 apud GASS \& SELINKER 2008: 137).

É importante ressaltar que, mais do que demonstrar as áreas de interferência advindas da interação de ambas as línguas, o foco da análise foi identificar os pontos de contato que auxiliam o processo de aprendizagem para falantes de português como língua materna, visto que, segundo HUFEISEN (1993), a transferência positiva passa a ser maior do que a interferência linguística, a partir do momento que os aprendizes estão conscientes dos paralelos existentes entre as línguas.

Tal como assinalado por NEUNER \& KURSIŠA (2006: 4), a questão da consciência linguística na aula de língua estrangeira é fundamental e deve ser incentivada desde as primeiras aulas, de forma que a comparação ativa dos sistemas linguísticos alemão/inglês (ou outras línguas aprendidas anteriormente) seja inserida no processo de aprendizagem. Isso é especialmente válido para as áreas da gramática e do vocabulário, cujo conhecimento prévio do inglês permite um acesso mais rápido ao alemão. A partir desse auxílio, pode-se, principalmente nos níveis iniciais da aprendizagem, construir um vocabulário razoável e desenvolver procedimentos para a compreensão de textos. 
Ferrari, B. - A influência do inglês no processo de ensino/ aprendizagem de alemão

O campo de investigação na área de ensino/aprendizagem de terceiras línguas é vasto e ainda são poucos os que se dedicam a estudar as condições e as consequências da aprendizagem de diversas línguas pelo mesmo sujeito, em especial no Brasil. Dessa forma, são relevantes estudos que tratem especificamente das consequências sociolinguísticas decorrentes da aprendizagem de Alemão após Inglês no país e do desenvolvimento de métodos de investigação especiais para a área da L3, em especial os que envolvam a análise contrastiva português/inglês/alemão. Partindo dos estudos que trabalham a aprendizagem de L3, podem ser desenvolvidas pesquisas sobre a influência do inglês no alemão em relação às capacidades linguísticas dos aprendizes (ler, escrever, ouvir e falar), bem como a investigação sobre o papel dos fatores de influência (p. ex. psicotipologia) nas transferências inglês/alemão. Adicionalmente, o desenvolvimento de uma didática de L3 que envolva a elaboração de materiais didáticos adaptados para aprendizes brasileiros parece interessante, especialmente se levados em consideração aprendizes mais velhos e que dispõem de um repertório linguístico composto por mais de uma língua estrangeira.

\section{Referências bibliográficas}

ALBERT, Ruth \& MARX, Nicole. Empirisches Arbeiten in Linguistik und Sprachlehrforschung. Anleitungen $z u$ quantitativen Studien von der Planungsphase bis zum Forschungsbericht. Tübingen, Narr, 2010

AUER, Peter \& WeI, Li (ed.). Handbook of Multilingualism and Multilingual Communication. Berlin, Mouton de Gruyter, 2007.

CAstilho, Ataliba T. de. "Funcionalismo e gramáticas do português brasileiro: novos desdobramentos." In: SouZA, Edson R. F. de (Org.). Gramática, texto e discurso. UFMS, no prelo, 2011, 11-29.

Conselho Da Europa. Quadro Europeu Comum de Referência para Línguas. Porto, Asa Editores, 2001.

DE ANGELIS, Gessica \& SELINKER, Larry. "Interlanguage Transfer and Competing Linguistic Systems in the Multilingual Mind." In: CENOZ, Jasone et al. (Ed.). Cross-linguistic influence in third language acquisition: psycholinguistic perspectives. Clevedon, Multilingual Matters, 2001, 42-58.

Duden. Die Grammatik. Mannheim, Duden, 2005.

GASS, Susan \& SELINKER, Larry. Second Language Acquisition: An Introductory Course. Londres, Routledge, 2008.

HUFEISEN, Britta. Englisch als erste und Deutsch als zweite Fremdsprache. Empirische Untersuchung zur fremdsprachlichen Interaktion. Frankfurt am Main, Lang, 1991.

HUFEISEN, Britta. "Fehleranalyse: Englisch als L2 und Deutsch als L3. " In: Iral 31, 1993, $242-$ 256. 
Ferrari, B. - A influência do inglês no processo de ensino/ aprendizagem de alemão

HUFEISEN, Britta. "L1, L2, L3, L4, Lx - alle gleich? Linguistische, lernerinterne und lernerexterne Faktoren in Modellen zum multiplen Spracherwerb." In: Zeitschrift für Interkulturellen Fremdsprachenunterricht [Online], 8(2/3), 2003, 97-109. http://www.spz.tu-darmstadt.de/projekt_ejournal/jg-08-2 3/docs/Hufeisen.pdf.(11/03/2011).

Kellerman, Eric \& SHARwOOD-SMith, Michael (Ed.). Crosslinguistic Influence in Second Language Acquisition. Nova York, Pergamon Press, 1986, 112-134.

KRUMM, Hans-Jürgen et al. Sprachenvielfalt. Babylonische Sprachverwirrung oder Mehrsprachigkeit als Chance? Innsbruck: Studienverlag, 2003.

KrUMM, Hans-Jürgen et al. Deutsch als Fremd- und Zweitsprache. Ein internationales Handbuch. Berlim, De Gruyter Mouton, 2010.

MARX, Nicole. "Denglisch bei nicht- indoeuropäischen Muttersprachlern?" In: Zeitschrift für Interkulturellen Fremdsprachenunterricht [Online], 5(1), 2000, 19p. http://spz1.spz.tudarmstadt.de/projekt_ejournal/jg-05 1/beitrag/marx.htm.(22/11/2010)

MURPHY, Shirin. "Second language transfer during third language acquisition." In: Working Papers in TESOL \& Applied Linguistics [Online], 3(2), 2003, 1-21. http://journals.tclibrary.org/index.php/tesol/article/viewFile/23/28 (17/04/2011)

NEUNER, Gerhard et al. Deutsch als zweite Fremdsprache. Berlim, Langenscheidt (Fernstudieneinheit 26), 2009.

NEUNER, Gerhard et al. "Deutsch als zweite Fremdsprache nach Englisch. Überlegungen zur Didaktik und Methodik und zur Lehrmaterialentwicklung für die 'Drittsprache Deutsch"' In: Deutsch als Fremdsprache 4, 1996, 211-217.

NEUNER, Gerhard \& KURSIŠA, Anta. Deutsch ist easy! Lehrerhandreichungen und Kopievorlagen "Deutsch nach Englisch" für den Anfangunterricht. Ismaning, Hueber Vorlag, 2006.

ODLIN, Terrence. Language transfer: cross-linguistic influence in language learning. Cambridge, Cambridge University Press, 1989.

RINGBOM, Håkan. "Crosslinguistic influence and the foreign language learning process." In: Kellerman, Eric \& SHARWOOD-SMITH, Michael (Ed.). Crosslinguistic Influence in Second Language Acquisition. Nova York, Pergamon Press, 1986, 150-162.

RINGBOM, Håkan. "Lexical transfer in L3 production” In: In: CENOZ, Jasone et al. (Ed.). Crosslinguistic influence in third language acquisition: psycholinguistic perspectives. Clevedon, Multilingual Matters, 2001, 59-68.

SAVEDRA, Mônica Maria Guimarães. "O desenvolvimento da língua alemã." In: BAGNO, Marcos \& Lagares, Xoán Carlos (Org.). Políticas da Norma e conflitos linguísticos. São Paulo, Parábola, 2011, 277-297.

SELINKER, Larry. "Interlanguage.” In: International Review of Applied Linguistics 10, 1972, 209-231.

SELINKER, Larry. Rediscovering Interlanguage. Londres, Longman, 1992.

SELINKER, Larry \& BAUMGARTNER-COHEN, B. "Multiple language acquisition. 'Damm it, why can't I keep these two languages apart? "' In: Language, Culture and Curriculum 8 (2), 1995, 115-121.

TAYLOR, John R. Possessives in English: An Exploration in Cognitive Grammar. Nova York, Oxford University Press, 2001.

Vogel, Thomas. "'Englisch und Deutsch gibt es immer Krieg': Sprachverarbeitungsprozesse beim Erwerb des Deutschen als Drittsprache. ” In: Zielsprache Deutsch 23 (2), 1992, 95-99.

VoLINA, S. "Deutsch als zweite Fremdsprache- ein Beispiel aus der Sowjetunion." In: BAUSCH, Karl R.; HEID, M. (Ed.). Das Lehren und Lernen von Deutsch als zweiter oder weiterer 
Ferrari, B. - A influência do inglês no processo de ensino/ aprendizagem de alemão

Fremdsprache: Spezifika, Probleme, Perspektiven. Manuskripte zur Sprachlehrforschung 32. Bochum, Brockmeyer, 1992.

WILLIAMS, Sarah \& HAMMABERG, Björn. "Languages switches in L3 production: implications for a polyglot speaking model. ” In: Applied Linguistics 19, 1998, 295-333.

Recebido em 19/06/2014

Aceito em 23/07/2014 